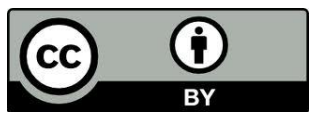

\title{
RELIGIOSIDADE E ESPACIALIDADES NO FOLGUEDO DO BOI:UMA FESTA COM VARIAÇÕES LOCAIS
}

\author{
Religiosity and Spatialities in the Brazilian's Folklore: a party with local variations
}

\begin{abstract}
Beatriz Helena Furlanetto
Doutoranda em Geografia na Universidade Federal do Paraná, pianista e professora assistente da Universidade Estadual do Paraná / Campus Escola de Música e Belas Artes do Paraná. e-mail: bia@sulbbs.com.br) Roberto Filizola Doutorando em Geografia na Universidade Federal do Paraná, professor do Setor de Educação da Universidade Federal do Paraná. (robertofilizola@ufpr.br)
\end{abstract}

RESUMO:O texto tem por objetivo investigar a religiosidade presente no folguedo do boi, uma das manifestações mais ricas do folclore brasileiro. Foram realizadas pesquisas de campo, bem como análise documental e bibliográfica acerca do bumba-meu-boi em São Luiz (MA), boibumbá em Parintins (AM) e Guajará-Mirim (RO), além do boi-de-mamão no litoral dos estados do Paraná e de Santa Catarina. O folguedo revela os atributos culturais de cada região e, enquanto criação coletiva é capaz de exprimir os sentidos que os sujeitos atribuem na sua relação com o espaço vivido e a natureza. No cotidiano dos artistas populares, a riqueza de suas vivências espaciais é contada e cantada nas múltiplas narrativas do folguedo. O mito da morte e ressurreição do boi é um tema que representa o ciclo da continuidade e aparece pelo país por meio de variações regionais, e também em escala local. A religiosidade se mescla à alegria e exuberância da festa, onde os atores sociais projetam suas visões de mundo e constroem suas concepções de identidade.

Palavras-chave: geografia cultural; religiosidade; folguedo do boi.

ABSTRACTC: The text aims to investigate the religiosity present in the party of the ox, one of the richest manifestations of Brazilian folklore. Field surveys were carried out, as well as documentary and bibliographic analysis about bumba-meu-boi in Maranhão, boi-bumbá in Amazonas, boi-de-mamão in Paraná and Santa Catarina. The party reveals the cultural attributes of each region and, while collective creation, is able to express the senses that subjects assign on his relationship with the space lived and nature. In the daily life of popular artists, its spatial experiences is told and sung in party's multiple narratives: the myth of the death and resurrection of the ox is a theme that represents the cycle of continuity and appears by the country with local variations. The religiosity that merges the joy and exuberance of the party, and the social actors design their worldviews and build their conceptions of identity.

Keywords: cultural geography; religiosity; Brazilian folklore. 


\section{1 - Introdução}

O folguedo ${ }^{1}$ do boi, uma das mais ricas manifestações do folclore brasileiro, constitui uma espécie de ópera popular, resultante da união de elementos das culturas européia, africana e indígena, no qual o boi é a principal figura de representação. Surgiu, aparentemente, no nordeste do Brasil e disseminou-se por quase todo território nacional, adquirindo diferentes nomes, ritmos, narrativas, formas de apresentação, indumentárias, personagens, instrumentos e temas em cada localidade. Enquanto no

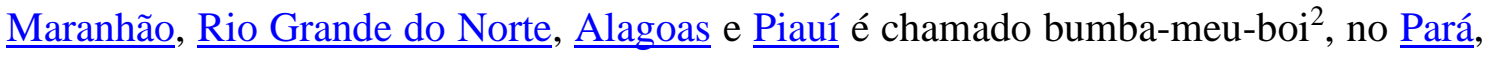
Amazonas e Rondônia é boi-bumbá, e no Paraná e Santa Catarina é boi-de-mamão ${ }^{3}$, entre outras denominações.

O enredo do folguedo do boi resgata uma história típica das relações sociais e econômicas da região nordestina durante o período colonial, marcadas pela monocultura da cana-de-açúcar, criação extensiva de gado bovino, com emprego de mão-de-obra escrava. Nas localidades brasileiras onde aparece o folguedo, a temática constante se desenvolve, basicamente, em torno de um rico fazendeiro, cujo boi de estimação é roubado por Pai Francisco, negro escravo da fazenda que mata o animal do seu senhor para satisfazer o desejo de sua esposa grávida, Mãe Catirina, de querer comer a língua do boi. Pajés e curandeiros são convocados para reanimar o animal e, quando o boi ressuscita urrando, os brincantes cantam e dançam em redor do boi, em uma enorme festa para comemorar o milagre.

As festas de boi realizadas em São Luiz do Maranhão, Parintins, Guajará-Mirim e no litoral do Paraná e Santa Catarina ilustram as inúmeras modificações que o folguedo adquiriu em cada localidade do Brasil. A partir de pesquisa de campo, análise

\footnotetext{
${ }^{1}$ Folguedos são festas populares de espírito lúdico que se realizam anualmente, em datas determinadas, em diversas regiões do Brasil. O bumba-meu-boi, para Meyer (1993), é considerado um folguedo popular. Mário de Andrade (1959) classifica o bumba-meu-boi como dança dramática brasileira, relacionando-o ao Reisado. Reisado é uma "encenação com canto e dança para comemorar o Dia de Reis, em quase todas as regiões do Brasil” (SADIE, 1994, p.775).

2 "Bumba" é uma interjeição onomatopaica que indica estrondo de pancada ou queda - bumba-meu-boi significa bate ou chifra meu boi.

${ }^{3}$ Conhecido anteriormente como boi-de-pau, boi-de-palha, boi-de-pano, boi-de-melão e finalmente boide-mamão, essa designação foi atribuída porque nas representações do folguedo eram utilizados mamões verdes para a confecção da cabeça do boi, de acordo com Cascudo (1954).
} 
documental e bibliográfica, constatou-se que a religiosidade, mesmo se apresentando de maneiras distintas, é um traço comum presente em todos os grupos investigados, como variações sobre um mesmo tema - o da morte e ressurreição, representado comicamente, mas também com dramacidade.

\section{2 - Religiosidade e espacilidades no folguedo do boi}

A religiosidade refere-se à condição humana de ser religioso. "A ideia de que o homem é religioso significa dizer que o homem é motivado pela fé em sua experiência na vida", afirma Rosendhal (2007, p.194). A natureza da geografia da religião consolida-se na exploração dos conceitos de sagrado e profano, e "a geografia da religião traduz-se, por outro lado, pelas suas dimensões de análise: a dimensão econômica, a dimensão política e a dimensão do lugar. [...] E é no espaço e tempo sagrados que essas dimensões se manifestam" (ROSENDHAL, 2007, p.220).

O sagrado e o profano constituem duas modalidades de ser no mundo e no cosmos, segundo Eliade (2008). O homem percebe o sagrado, pois este se manifesta como algo diferente do profano. A hierofania corresponde à revelação de algo sagrado, indica a sacralização de todo e qualquer objeto, a manifestação do transcendente pessoal. A manifestação do sagrado transforma qualquer coisa em outra coisa, qualquer ser em outro ser, estabelecendo uma ordem distinta em toda relação com o mundo - as coisas ditas sagradas são outras, embora permaneçam as mesmas. Assim, a referência do sagrado posiciona o homem diante de sua própria existência, contribuindo para um universo de relações ressignificado.

Embora suas contribuições para o entendimento dos fenômenos religiosos sejam muito valiosas, Eliade estabelece uma perspectiva dualista de mundo: sagrado e profano, sendo que, na negação do sagrado se reconhece o profano. Entretano, na apreensão das espacialidades religiosas do folguedo do boi, a dicotomia sagrado e profano parece diluída pelas relações sociais que se estabelecem nas práticas comunitárias.

É importante salientar que a investigação geográfica se mostra limitada quando circunscrita a uma interpretação espacial da prática religiosa ou do conjunto de objetos religiosos da paisagem, pois a geografia da religião "tem por objeto o fenômeno 
religioso visto como um espaço de relações objetivas e subjetivas consubstanciadas em formas simbólicas mediadas pela religião", esclarece Gil Filho (2007, p.210).

Considerando o homem como um animal simbólico, Cassirer (1994) afirma que todo conhecimento e toda a relação do homem com o mundo se dá no âmbito das diversas formas simbólicas, sendo elas a linguagem, o mito, a religião, a arte e a ciência. Portanto, o ser humano não vive apenas na realidade imediata, mas imerso em um universo simbólico.

Enquanto ser que simboliza, o homem supera a condição da vida biológica e se estabelece de modo cultural e também religioso. A pluralidade das expressões religiosas presentes no folguedo do boi no Norte, Nordeste e Sul do Brasil gera diferentes sociabilidades e espacialidades, conformando mundos simbólicos distintos que se manifestam na riqueza cultural de cada região do país.

Gil Filho (2009, p.263) destaca que "a geografia do sagrado estaria muito mais afeta à rede de relações em torno da experiência do sagrado do que propriamente às molduras perenes de um espaço sagrado coisificado". Portanto, a rede de relações geradas pelo folguedo do boi pode permitir a identificação de uma espacialidade específica própria da experiência do sagrado.

No plano fenomênico, o sagrado se apresenta em uma diversidade de relações que nos possibilita entendê-lo enquanto representação, segundo Gil Filho (2008), que concebe quatro instâncias de análise do fenômeno religioso: a paisagem religiosa, o sistema simbólico, as escrituras e tradições sagradas, o sentimento religioso.

Então, o sagrado pode ser entendido como qualitativo inerente ao fenômeno religioso, que perpassa as instâncias de análise descritas e, assim, sob a ótica fenomenológica, também significa os modos típicos que caracterizam o fenômeno enquanto religioso, a despeito da pluralidade de suas manifestações (GIL FILHO, 2008, p.33).

Nesse sentido, no folguedo do boi é possível apreender os elementos religiosos que conferem singularidades, peculiaridades ao mundo religioso. Como um dos atributos da espacialidade, o sagrado "se traduz através de práticas culturais eivadas de sentido religioso, de crenças, mitos e divindades. Práticas culturais e, portanto, sociais que marcam a existência dos homens e sua organização em sociedades em sua expressão espacial" (CORRÊA, 2008, p.163).

Entre as antinomias da experiência humana, a da vida e da morte mostra-se como o dilema mais doloroso e fundamental para os homens, de acordo com Tuan 
(1980, p.19): “os mitos, lendas e contos folclóricos das mais diferentes partes do mundo têm sido interpretados como tentativas diversas para tornar a morte inteligível e aceitável". No mito, é possível imaginar um estado no qual uma pessoa morta continua a viver ou pode retornar à vida.

$\mathrm{O}$ auto do boi representa o ciclo da continuidade, pois o boi morre para ressuscitar todo ano: um enredo que parece transfigurar a morte em alívio e esperança, uma circularidade na qual vida e morte se encontram no milagre da ressurreição, e o boi se reveste de um caráter sobrenatural - o encontro do sagrado com o profano.

Embora o bumba-meu-boi seja classificado como folguedo profano, sua relação com os santos católicos é bastante marcante. No Maranhão, a festa acontece todos os anos no mês de junho, atraindo moradores e turistas para os inúmeros arraiais de todo o estado. A brincadeira se prolonga por um extenso ciclo festivo, o qual pode levar meses na realização de ensaios, batizado, apresentações públicas, e a morte do boi. As formas de festejar são várias, associadas a regiões e tradições culturais específicas que resultam na pluralidade de estilos ou sotaques que caracteriza o bumba-meu-boi maranhense, entre os quais os mais conhecidos são os sotaques de matraca, zabumba, baixada, orquestra e costa-de-mão. Esses sotaques apresentam diferenças em relação a ritmo, coreografia, instrumentos musicais, personagens e indumentárias.

Em São Luiz do Maranhão, mais que uma explosão de alegria, a festa é quase uma forma de oração, é compromisso sagrado com São João, pois muitos grupos de boi nasceram de uma promessa feita por seus fundadores, em momento de aflição, ao glorioso santo. A religiosidade se expressa nas imagens de São João, São Pedro, São Marçal e Santo Antonio afixadas em destaque nos arraiais espalhados pela cidade, nos santuários e altares desses espaços - onde as estátuas dos quatro santos permanecem ornamentadas com flores e velas, oferecidas pelos devotos e pagadores de promessa como também nas barracas e tabuleiros com o nome dos santos, nas letras das toadas dos cantadores.

"Neste sentido, já não há separação entre o sagrado e o profano, tudo faz parte de um mesmo universo de relações de trocas, construindo uma intimidade sacralizada pelo cotidiano", afirmam Ferreira e Silva $(2008$, p.8). Ao observar as relações que se constroem entre os brincantes e a imagem do boi, nos festejos juninos de São Luiz, esses autores concluem que o boi acaba revestido de uma característica sobrenatural, um 
portador das oferendas da comunidade a Deus. “O boi se torna o 'guardião' da harmonia e dançar com ele, acompanhar o seu cortejo ou tocá-lo é para alguns uma situação que ultrapassa o simples ato do lazer que a 'brincadeira' proporciona”, segundo Ferreira e Silva (2008, p.5-6), simbolizando tanto a fartura quanto a esperança por condições melhores.

Enquanto a proximidade aos santos católicos parece se destacar em São Luiz do Maranhão, em Parintins, cidade do interior amazonense localizada na ilha de Tupinambarana, a religiosidade se expressa nas lendas e rituais indígenas.

O Festival Folclórico de Parintins ${ }^{4}$ tem como particularidade a disputa entre os grupos de boi, que divide o município, seus moradores e os turistas entre as cores azul (e branco) e vermelho (e branco), das agremiações do "Boi Caprichoso" e "Boi Garantido", respectivamente. O festival é um espetáculo tecido com o encanto das toadas e lendas, representações de rituais indígenas e celebrações tribais povoadas por seres míticos amazônicos, como botos, iaras, curupiras, caiporas, anhangás, cobrasgrandes, uma expressão máxima da autenticidade cultural da região Norte do Brasil. A história de Parintins, suas riquezas naturais e os costumes dos ribeirinhos são explorados pelos grupos de boi: nas toadas ${ }^{5}$, indumentárias, alegorias e encenações, estão presentes elementos essenciais à construção de identidades territoriais.

A territorialidade, para $\operatorname{Sack}^{6}$ (1980), é uma estratégia geográfica para controlar pessoas e coisas através do controle da área, e envolve uma forma de classificação por área, uma forma de comunicação por fronteira e uma forma de imposição de controle sobre o acesso a uma área e às coisas dentro dela. Esses três fatores de territorialidade podem ser encontrados em todas as sociedades, desde as primeiras civilizações até às sociedades mais complexas. Portanto, para o autor, a territorialidade abrange uma série de elementos que, combinados entre si, formam especificidades diversas.

\footnotetext{
${ }^{4}$ Considerado a maior manifestação cultural do Norte brasileiro, o Festival Folclórico de Parintins acontece todos os anos no mês de junho. Os grupos de boi se apresentam durante três noites no Centro Cultural e Esportivo Amazonino Mendes, conhecido como Bumbódromo. 5 As toadas são composições musicais feitas para a apresentação do boi-bumbá, constituindo o fio
condutor do espetáculo.

${ }^{6}$ O geógrafo Robert D. Sack (1980, p.19) define a territorialidade como "the attempt by an individual or group to affect, influence, or control people, phenomena, and relationships, by delimiting and asserting control over a geographic area".
} 
Essa perspectiva abrangente da territorialidade apresentada por Sack mostra-se pertinente à investigação do festival parintinense, pois a disputa entre os grupos de boi estabelece uma cisão socioespacial, caracterizando territorialidades distintas. A divisão espacial que estabelece um lado do bumbódromo para os agremiados do "Boi Caprichoso" e o outro lado para o "Boi Garantido", evidencia a classificação por área; as cores e adereços usados pelos torcedores de cada grupo de boi também funcionam como símbolos de fronteiras; e o pertencimento a determinado grupo de boi parece corroborar o controle desse grupo sobre o acesso a uma área específica e as relações sociais dentro dela.

Os grupos de boi envolvem a comunidade, criando uma história em comum, despertando sentimentos, tecendo laços identitários: compartilhando as mesmas toadas, cantando e torcendo juntos por um dos grupos de boi, os parintinenses constroem seus valores e estabelecem vínculos territoriais, já que a música retrata a cultura e a memória do povo, possibilitando uma forma de comunicação na inter-relação entre indivíduo e grupo. Ressalta-se a utilização da música para o estabelecimento de vínculos territoriais. Como aponta Kong (2009, p.164), "a música é um agente ativo na produção e reprodução social e espacial da vida cotidiana", e pode ser utilizada ideologicamente para efeito de socialização política.

Percebe-se que o boi-bumbá de Parintins cria territorialidades em que os atores projetam suas concepções de mundo e constroem suas identidades, representadas atualmente como identidade amazônica. Nesse sentido, o folguedo do boi contribui para o estabelecimento de vínculos territoriais, principalmente através das toadas, pois a música, como uma forma de comunicação cultural, é um meio pelo qual identidades são construídas.

A territorialidade pode decorrer, ainda, de uma competição por coisas e relações no espaço, e não necessariamente por uma competição pelo mesmo espaço, segundo Sack (1980). Isso parece ocorrer em Parintins: a disputa entre os grupos de boi se evidencia, principalmente, na busca pelo reconhecimento e pela premiação como o melhor grupo, bem como no esforço para conquistar novos associados.

Vale a pena comentar que a particular disputa entre os grupos de boi em Parintins teve início em 1966, e tem sido reproduzida, em menor escala, em outras 
cidades amazônicas, como Nova Olinda do Norte (AM), Guajará-Mirim (RO) e em Porto Velho (RO).

A festa de crescente destaque em Rondônia encontra-se associada ao Festival Folclórico de Guajará-Mirim, mais conhecido por "Duelo na Fronteira", dada a localização do município na divisa do Brasil com a Bolívia.

Assim como ocorre em Parintins, o "Duelo na Fronteira" é disputado por duas agremiações, igualmente caracterizadas pelas cores azul (e branco) e vermelho (e branco), tratando-se, respectivamente, do Boi Malhadinho e do Boi Flor do Campo. É importante assinalar que, muito embora as duas agremiações rondonienses tenham se espelhado nos grupos de Parintins, quando da sua criação em 1995, as brincadeiras de boi integravam o cotidiano do município desde os anos de 1960. Àquela época, o folguedo mantinha as particularidades do bumba-meu-boi, de raízes nordestinas, e a brincadeira acontecia nas ruas da cidade, no mês de junho, com o envolvimento dos seus moradores.

O "Duelo na Fronteira" exprime, com força crescente, os sentidos que os sujeitos atribuem à sua relação com o espaço amazônico, sua cultura e seus componentes paisagísticos. Seja por meio das toadas, das indumentárias, das alegorias e das encenações, tanto a história de Guajará-Mirim e de Rondônia, como as lendas e os contos amazônicos, revelam que a cultura desempenha um papel na estruturação do espaço local e na formação identitária dos sujeitos. Sendo assim, o festejo possibilita a construção de territorialidades específicas, com apropriação de elementos simbólicos.

Tais territorialidades podem ser apreendidas em diferentes escalas e em distintas temporalidades. Fora do período do festival, o bumbódromo parece perder seu poder simbólico, reduzido que fica a uma estrutura de concreto. Entretanto, o entorno do Colégio Estadual Almirante Tamandaré, berço do Boi Flor do Campo, é marcado pela presença das cores vermelho e branco, simbolizando uma fronteira que se torna tão mais evidente quanto mais se aproxima a época da festa, na segunda semana de agosto.

"Do outro lado" da Avenida XV de Novembro, verdadeiro eixo estruturador da cidade, parece situar-se o domínio do azul e branco, ou seja, valores e identidades territoriais são construídos simultaneamente. Percebe-se, assim, que a inscrição simbólica da fronteira no espaço é força demarcatória de territórios. Contudo, sua porosidade coloca em xeque a conotação de espaço fechado, controlado. O espaço 
social acaba se configurando num encontro singular entre pessoas e lugares, tornando-se um campo simbólico, revelador de relações sociais das mais variadas matizes.

Convém comentar que esse campo simbólico é produto de um passado comum. Enquanto realidade, o espaço social guajaramirense formou-se "por epigênese, por adições e modificações, e não a partir de uma pré-formação" (VEYNE, 2011, p.98). As agremiações do boi também se inserem nesse contexto, bem como as cores azul, branco e vermelho possuem uma conotação religiosa ${ }^{7}$ que remonta ao passado: o Sagrado Coração de Jesus ${ }^{8}$ (vermelho) e a Congregação Mariana ${ }^{9}$ (azul), ilustrando a fusão dos mitos e ritos tribais indígenas a símbolos religiosos do Cristianismo.

A tradição cristã marca presença, ainda, no folguedo do boi na região sul do Brasil. Em Santa Catarina o boi-de-mamão é uma brincadeira divertida e muito apreciada pela população, e constatou-se a existência de aproximadamente quinze grupos de boi na ilha de Florianópolis que, além de manter a tradição cultural, se destacam como atração turística local. No Paraná, o folguedo do boi se mostra como uma prática social com pouca visibilidade: uma pequena parte da população mantém viva essa manifestação cultural e poucos paranaenses parecem conhecê-la.

Foram identificados quatro grupos que brincam com o boi nas comemorações carnavalescas e festas religiosas do litoral paranaense: os grupos "Boi do Norte" e "Boi Barroso", que se constituem como blocos carnavalescos na cidade de Antonina; o "Boi

\footnotetext{
7 “O primeiro caráter do simbolismo das cores é a sua universalidade, não só geográfica mas também em todos os níveis do ser e do conhecimento, cosmológico, psicológico, místico, etc. As interpretações podem variar. $\mathrm{O}$ vermelho, por exemplo, recebeu diversas significações conforme as culturas. [...] A arte cristã acabou por atribuir, num processo paulatino e sem fazer disso regra absoluta, o branco ao Pai, o azul ao Filho, o vermelho ao Espírito Santo; o verde à esperança, o branco à fé, o vermelho ao amor e à caridade, o preto à penitência, o branco à castidade", segundo Chevalier (2009, p.275-277).
}

${ }^{8}$ Sagrado Coração de Jesus é uma devoção cultivada pela Igreja Católica ao longo de todas as primeiras sextas-feiras de cada mês, que consiste na veneração do Coração de Jesus, do mais íntimo de Seu Amor. Entre as cores litúrgicas na Igreja Católica Apostólica Romana, o vermelho lembra o fogo do Espírito Santo e também o sangue, sendo a cor dos mártires e da sexta-feira da Paixão.

${ }^{9}$ Congregação Mariana é uma associação pública de leigos católicos, formada por cristãos que procuram seguir melhor o Cristianismo através de uma vida consagrada à Mãe de Deus, a Virgem Maria. As Congregações Marianas tiveram iníco em 1563, em Roma, e se espalharam pelo mundo. Os Congregados Marianos do Brasil podem ser reconhecidos nas reuniões ou celebrações da igreja pela fita que pende do pescoço da cor azul (cor litúrgica da Virgem Maria), em cuja extremidade está uma medalha prateada com a imagem do Nosso Senhor Jesus Cristo de um lado e, do outro, a da Virgem Maria. 
de Mandicuera" da Ilha de Valadares, em Paranaguá; e o "Boi-de-Mamão do Grupo Folclórico de Guaratuba".

Aparentemente, migrantes de Santa Catarina que se fixaram no litoral do Paraná trouxeram a tradição do folguedo do boi. Nos dois estados, a comicidade do boi-demamão, ilustrada nas apresentações de personagens e animais fantásticos anunciados pelos cantadores, parece ocultar os aspectos religiosos que marcam o folguedo. O tema da morte e ressurreição revela, por si só, uma dimensão simbólica do sagrado, mesmo porque, a época de encenação do boi nos seus primórdios desenrolava-se do Natal à festa de Reis. Na atualidade, se estende para além, cobrindo as comemorações carnavalescas, e contemplando também apresentações em festas tradicionais religiosas, como a centenária Festa do Divino em Guaratuba, sugerindo, destarte, uma proximidade de sua manifestação com aspectos religiosos.

As espacialidades constituídas pelos grupos de boi contemplam referências religiosas, como a pomba branca ${ }^{10}$ que se destaca na decoração da Festa do Divino em Guaratuba e na capela do Ponto de Cultura Mandicuera, em Paranaguá, onde os grupos de boi se apresentam, marcando a forte presença da igreja católica.

Convém recordar que o boi era um animal sagrado na Grécia, símbolo de bondade, de calma e de força tranquila, ligado à agricultura e à aração, afirma Ronecker (1997). Considerado um elemento do culto da força e da virilidade, o boi era venerado pelos povos primitivos, como símbolo de trabalho e de fertilidade. Ao referir-se à decorativa armação do boi como o centro de interesse do bumba-meu-boi, Cascudo (1954) discute a possibilidade de uma simbologia religiosa, no plano totêmico, uma herança da zoolatria pretérita.

O símbolo do boi aparece entre as expressões populares mais difundidas no Brasil, como as histórias de bois encantados, as melodias folclóricas, as danças e brincadeiras de boi, de norte a sul do país. Mesmo velada, a religiosidade parece ser a raiz dessas tradições e, mesclada às vivências de determinados grupos sociais em diferentes contextos espaciotemporais, essas práticas populares convivem com a mudança, em constante transformação.

\section{3 - Considerações Finais}

\footnotetext{
${ }^{10}$ No Cristianismo, a pomba branca é o símbolo do Divino Espírito Santo. Ao longo de toda a simbologia judaico-cristã, a pomba é, fundamentalmente, um símbolo de pureza, simplicidade, paz, harmonia e esperança, conforme Chevalier (2009).
} 
O folguedo do boi adquiriu, e continua adquirindo, inúmeras modificações por todo país, compondo parte das manifestações da sociabilidade local, representando as visões de mundo, os valores éticos e estéticos de determinadas comunidades. Enquanto criação coletiva, o folguedo revela os atributos culturais de cada região e exprime os sentidos que os sujeitos atribuem à sua relação com o espaço e com a natureza.

No cotidiano dos artistas populares, a riqueza do espaço vivido é contada e cantada nas múltiplas narrativas do folguedo: o mito da morte e ressurreição do boi é um tema que representa o ciclo da continuidade e aparece em quase todo país, por meio de variações regionais, e também em escala local. A presença dos símbolos ligados à tradição cristã, somada às múltiplas expressões culturais que caracterizam a arte popular brasileira, aparentemente, encontram-se presentes em todas as localidades investigadas.

A religiosidade se mescla à alegria e exuberância da festa, na qual os atores sociais projetam suas visões de mundo e constroem suas concepções identitárias. Nas regiões consideradas, o folguedo do boi ilustra o encontro do sagrado e do profano, revestido de riqueza e diversidade. $\mathrm{O}$ aspecto cômico se destaca na Região Sul do país, enquanto no Norte e Nordeste predomina o enfoque dramático ao tema da morte e ressurreição.

As festas populares, como o folguedo do boi, são manifestações culturais que constroem espacialidades próprias e valores territoriais, e se constitui como importante campo para investigação da geografia cultural e da social, podendo contribuir para um entendimento mais sensível da realidade brasileira, quiçá animando uma geografia das festas.

\section{Referências Bibliográficas}

ANDRADE, Mário de. Danças dramáticas do Brasil. São Paulo: Livraria Martins Editora, $1^{\circ}$ vol., 1959.

CASCUDO, Luís da Câmara. Dicionário do folclore brasileiro. Rio de Janeiro: Ministério da Educação e Cultura, 1954.

CASSIRER, Ernst. Ensaio sobre o homem: introdução a uma filosofia da cultura humana. Trad. Tomás R. Bueno. São Paulo: Martins Fontes, 1994. 
CHEVALIER, Jean. Dicionário de símbolos: mitos, sonhos, costumes, gestos, formas, figuras, cores, números. Trad. Vera da Costa e Silva. 24 ed. Rio de Janeiro: José Olympio, 2009.

CORRÊA, Aureanice de Mello. Espacialidades do sagrado. p. 163-179. In SERPA, Angelo (org.) Espaços culturais: vivências, imaginações e representações. Salvador: EDUFBA, 2008.

ELIADE, Mircea. O sagrado e o profano: a essência das religiões. Trad. Rogério Fernandes. 2 ed. São Paulo: Martins Fontes, 2008.

FERREIRA, Carla George Silva; SILVA, Carlos Benedito Rodrigues da. Festejar com fé: o bumba-meu-boi maranhense uma cumplicidade com São João. In: Revista Brasileira do Caribe. Salvador: $2008 . \quad$ Disponível em: www.revistabrasileiradocaribe.org/ CarlaFerreiraCarlosSilva. Acesso em: 07/06/2009.

GIL FILHO, Sylvio Fausto. Geografia da Religião: reconstruções teóricas sob o idealismo crítico. In: Kozel, Salete; COSTA SILVA, Josué da; GIL FILHO, Fausto (orgs.). Da percepção e cognição à representação: reconstruções teóricas da Geografia Cultural e Humanista. São Paulo: Terceira Margem; Curitiba: NEER, 2007.

GIL FILHO, Sylvio Fausto. Por uma geografia do sagrado. p. 253-265. In: Elementos de epistemologia da geografia contemporânea. MENDONÇA, F. KOZEL, S. (orgs.) Curitiba: Ed. da UFPR, 2009.

GIL FILHO, Sylvio Fausto. Espaço sagrado: estudos em geografia da religião. Curitiba: Ibpex, 2008.

KONG, Lily. Música popular nas análises geográficas. p.129-175. In: CORRÊA, Roberto L.; ROSENDHAL, Zeny (orgs.). Cinema, música e espaço. Rio de Janeiro: EdUERJ, 2009.

MEYER, Marlyse. Caminhos do imaginário no Brasil. São Paulo: Ed. da Universidade de São Paulo, 1993.

RONECKER, Jean-Paul. O simbolismo animal: mitos, crenças, lendas, arquétipos, folclore, imaginário. Trad. Benôni Lemos. São Paulo: Paulus, 1997.

ROSENDHAL, Zeny. Espaço, cultura e religião: dimensões de análise. p.187-224. In: CORREAA, Roberto Lobato; ROSENDHAL, Zeny (orgs.). Introdução à geografia cultural. 2 ed. Rio de Janeiro: Bertrand Brasil, 2007.

SACK, Robert David. Human territoriality: Its theory and history. Cambridge: Cambridge University Press, 1980.

SADIE, Stanley. Dicionário Grove de Música. Edição concisa. Trad. Eduardo F. Alves. Rio de Janeiro: Jorge Zahar Ed. 1994. 
TUAN, Yi-Fu. Topofilia: um estudo da percepção, atitudes e valores do meio ambiente. Trad. Lívia de Oliveira. São Paulo: Difel, 1980.

VEYNE, Paul. Foucault: seu pensamento, sua pessoa. Rio de Janeiro: Civilização Brasileira, 2011.

Recebido: $18 / 04 / 2012$

Received: 04/18/2011

Aprovado: $02 / 07 / 2012$

Approved: 07/02/2012 